IZA DP No. 5648

Altruism in Society: Evidence from a Natural Experiment Involving Commuters

Redzo Mujcic

Paul Frijters

April 2011 


\title{
Altruism in Society: Evidence from a Natural Experiment Involving Commuters
}

\author{
Redzo Mujcic \\ University of Queensland \\ Paul Frijters \\ University of Queensland \\ and IZA
}
April 2011
IZA
P.O. Box 7240
53072 Bonn
Germany

Discussion Paper No. 5648

Phone: +49-228-3894-0

Fax: +49-228-3894-180

E-mail: iza@iza.org

\begin{abstract}
Any opinions expressed here are those of the author(s) and not those of IZA. Research published in this series may include views on policy, but the institute itself takes no institutional policy positions.

The Institute for the Study of Labor (IZA) in Bonn is a local and virtual international research center and a place of communication between science, politics and business. IZA is an independent nonprofit organization supported by Deutsche Post Foundation. The center is associated with the University of Bonn and offers a stimulating research environment through its international network, workshops and conferences, data service, project support, research visits and doctoral program. IZA engages in (i) original and internationally competitive research in all fields of labor economics, (ii) development of policy concepts, and (iii) dissemination of research results and concepts to the interested public.
\end{abstract}

IZA Discussion Papers often represent preliminary work and are circulated to encourage discussion. Citation of such a paper should account for its provisional character. A revised version may be available directly from the author. 
IZA Discussion Paper No. 5648

April 2011

\section{ABSTRACT}

\section{Altruism in Society: Evidence from a Natural Experiment Involving Commuters ${ }^{*}$}

We study social preferences in the form of altruism using data on 959 interactions between random commuters at selected traffic intersections in the city of Brisbane, Australia. By observing real decisions of individual commuters on whether to stop (give way) for others, we find evidence of (i) gender discrimination by both men and women, with women discriminating relatively more against the same sex than men, and men discriminating in favour of the opposite sex more than women; (ii) status-seeking and envy, with individuals who drive a more luxury motor vehicle having a 0.18 lower probability of receiving a kind treatment from others of low status, however this result improves when the decision maker is also of high status; (iii) strong peer effects, with those commuters accompanied by other passengers being 25 percent more likely to sacrifice for others; and (iv) an age effect, with mature-aged people eliciting a higher degree of altruism.

JEL Classification: D64, D03, C90

Keywords: altruism, social interaction, social discrimination, status, peer effects, commuters

Corresponding author:

Paul Frijters

University of Queensland

School of Economics

Level 6, Colin Clark Building

St Lucia, Brisbane, Qld 4072

Australia

E-mail: p.frijters@uq.edu.au

\footnotetext{
*We thank Gary S. Becker for helpful comments and suggestions. Any remaining errors are our own.
} 


\section{Introduction}

The key question of interest in this paper is: Who stops for whom at traffic intersections? We use information on 959 social interactions between random commuters in the city of Brisbane, Australia, to study this type of prosocial behaviour. The observation plan is illustrated in Figure 1. Individuals $i$ and $j$ are commuters travelling to a destination located in the south, where $j$ awaits to merge onto the main road. The waiting and commuting time of individual $j$ can be reduced if individual $i$ stops and gives way. This sacrifice by $i$ that benefits $j$ is termed unconditional kindness or altruism (Becker 1974) ${ }^{1}$ By observing a limited set of commuter characteristics (such as gender, age, type of car, copassengers) we deduce the relative level of altruism conditional on both the characteristics of the individual who might stop and the individual being stopped for.

The natural experiment inherent in random commuter interactions provides a simple and hitherto untapped source of information about altruistic preferences. It augments a large literature on altruism and other-regarding preferences based on behaviour in experimental laboratories (see Fehr and Schmidt 2006; Levitt and List 2007; Cooper and Kagel 2009). In these experiments, student subjects are often asked to interact with others in a number of predefined and monitored games such as the dictator game and the public goods provision game, with the observed behavior used to estimate preference parameters of interest. ${ }^{2}$ Although lab experiments allow the researcher to control a number of key variables, such settings have several drawbacks, including the limited realism of the laboratory environment, the selectivity of participants, the unusual degree of scrutiny, and the high level of contextual information provided to participants (Levitt and List 2007).

To overcome the limitations of laboratory experiments, a number of researchers have recently turned to less artificial settings by inferring social preferences from field-generated data (that is, by using natural and field experiments). Such studies have focused, among other issues, on social preferences and outcomes in actual market transactions, for example, at a sportscard show (List 2006a); mate preferences and social discrimination in online and speed dating markets (Fisman et al. 2006, 2008; Hitsch et al. 2010); altruism and door-to-door charitable fundraising (Landry et al. 2006; Karlan and List 2007; Shang and Croson 2009); social preferences and productivity among fishermen (Carpenter and Seki 2010); social discrimination, cooperation, and individual preferences on television game shows (Berk et al. 1996; Beetsma and Schotman 2001; Levitt 2004; List 2006b); altruism and reciprocity in social networks (Leider et al. 2009); altruistic (rescue) behaviour during the Holocaust (Hoffman 2010); and altruism among volunteer firefighters (Carpenter and Myers 2010) ${ }^{3}$ The present study firmly belongs to this literature by adding the natural pairing of commuters in a familiar day-to-day setting as the source of random variation used to infer altruistic preferences.

The data and methodology used in this paper are further explained in Section 2.

\footnotetext{
${ }^{1}$ Throughout the paper, the words and phrases: 'altruistic act', 'kind act', 'sacrifice', 'generous', and 'stop' are used interchangeably, and all refer to the behaviour illustrated in Figure 1.

${ }^{2}$ For a summary and examples of experimental games used to measure social preferences, see Levitt and List (2007).

${ }^{3}$ For a non-technical review and discussion of experimental economics and altruistic behaviour, see Chapter 3 of SuperFreakonomics by Steven D. Levitt and Stephen J. Dubner (2009).
} 
Section 3 presents the raw descriptive results and estimation results from more formal modelling.

The first subquestion that we pose is 'Who is more altruistic?', which we answer by simply looking at the proportion of times individuals with different characteristics stop for others. Of particular interest is whether individuals in more expensive and larger motor vehicles (e.g. a sport-utility vehicle) are more, or less, likely to make a sacrifice for others. A recent study by Hoffman (2010), based on rescue data from the Holocaust, finds altruism to increase in income. Similarly, Andreoni (2006) finds a U-shaped relationship between income and charitable giving among households in the United States. Does the same pattern hold for commuters?

The second subquestion is whether the characteristics of the waiting individual matter, in particular their gender and social status as measured by the expensiveness of their car. The possible importance of gender follows the idea of cross-gender preferences, including possible gender discrimination (Becker 1971). The importance of the social status of the waiting individual (commuter $j$ ) informs us about the possibility that individuals either regard everyone they might stop for as equal (in which case the quality of the car should not matter), or that individuals are more envious toward the well-off and hence stop less often for such individuals (akin to the status-seeking hypothesis of Veblen, 1899). That is, an individual who is observed driving an expensive, or prestigious, motor vehicle (e.g. a brand new BMW) is quite likely to be a member of a wealthy household and hold high status within his or her social reference group (and society in general). Individuals with high status have access to clubs, friends, and goods that are not available to those with low status (Becker et. al 2005; Frank 1999). Then, other commuters' envy of such 'goods' could lead to a lower propensity to stop for them. Clark et al. (2008) find statusseeking to play a significant role in human behaviour and social preferences in general 4 Similarly, Johansson-Stenman and Martinsson (2006), in their study entitled 'Honestly, why are you driving a BMW?', find evidence of strong individual (car buyer) awareness about the importance of status concerns in society. From these studies, one would expect random commuters to elicit a lower propensity to stop for more expensive cars relative to inexpensive ones.

The final subquestion examines whether there are peer effects in altruism. We try to get at the notion of peer effects in two ways: (i) whether it matters if there is someone else inside of the stopping vehicle apart from the driver (e.g. family members, friends, or work colleagues), and (ii) whether it matters if the car in front of the decision maker has stopped for someone or not. This latter type of situation is only salient in a certain percentage of the observations, namely where the previous car (commuter ' $i-1$ ') was observable by the decison maker (commuter $i$ ) and when the former commuter had an opportunity to stop (that is, a commuter $j$ was present). Some field studies suggest that monitoring by peers would increase altruistic behaviour. For example, Bandiera et al. (2005) examine data from a UK based fruit farm, whereby workers who were monitored by their fellow co-workers behaved in a lot more altruistic manner by reducing the amount of negative externality produced, i.e. workers internalised the effects of their behavior on

\footnotetext{
${ }^{4}$ As a notable example, Luttmer (2005), using panel data on self-reported happiness in the United States, finds that the happiness of individuals is negatively affected by the earnings of others residing in the same area.
} 


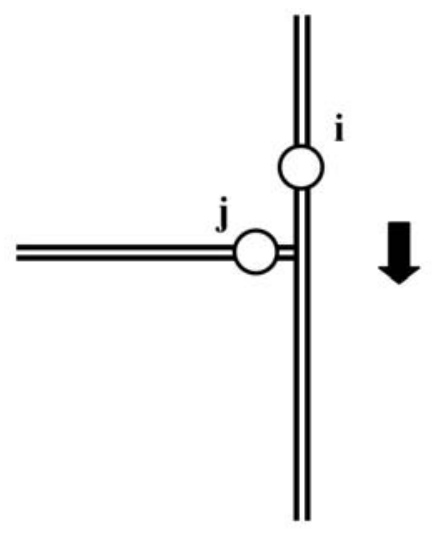

(a) Initial interaction

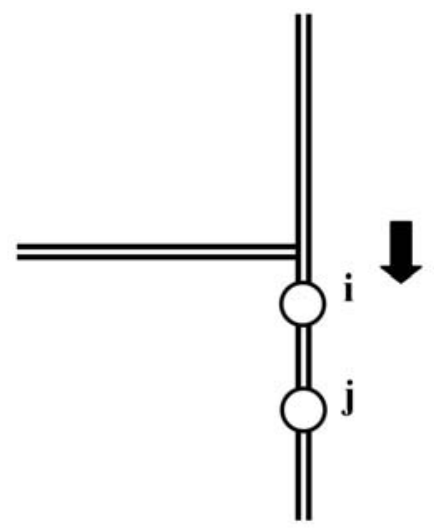

(b) Altruism

Figure 1: Social Interaction between $i$ and $j$

colleagues. One would expect similar behaviour among commuters, and hence that both the presence of a passenger and a positive prior example would lead to more altruistic behaviour. Section 4 discusses some policy implications and concludes.

\section{Data and Methodology}

\subsection{Data}

The data in this paper are based on observed social interactions between commuters at selected traffic intersections in the city of Brisbane, Australia. To capture the intended social interaction in Figure 1, we selected intersections that satisfied the following two conditions: (1) the speed of traffic flow was slow enough for commuter $i$ to be able to observe commuter $j$ as he or she approached the initial position (Figure 2). That is, $i$ was able to clearly observe the other driver and the type of motor vehicle before making a decision to stop or not. And, (2) commuter $j$ was positioned and waiting at an intersection where there were no traffic lights present (except for a 'give way' sign).

The first condition was fulfilled by observing commuters during peak, or rush hour, traffic times: between 0700 and 0900 AEST, and between 1700 and 1900 AEST. Moreover, the selected traffic intersections each had a traffic light or roundabout (circular junction) positioned further south on the main road (see Figure 2). Such road obstacles (by promoting congestion) ensured that commuter $i$ was travelling at a low speed (approximately between 5 and $25 \mathrm{~km} / \mathrm{h}$ ) when approaching commuter $j$. Overall, commuter $i$ had 5 to 10 seconds of clear vision and decision time.

The second condition removes any traffic rules that eliminate the possibility of observing the social interaction of interest. After a careful and long search, we were able to locate three intersections with such 'traffic-rule free' settings. The chosen locations were based in different suburbs, or neighbourhoods $5^{5}$ In order to ensure minimal distraction,

\footnotetext{
${ }^{5}$ The three suburbs were Coorparoo ( $5 \mathrm{~km}$ from CBD), Moorooka (9km from CBD), and Woolloongabba (4km from CBD).
} 


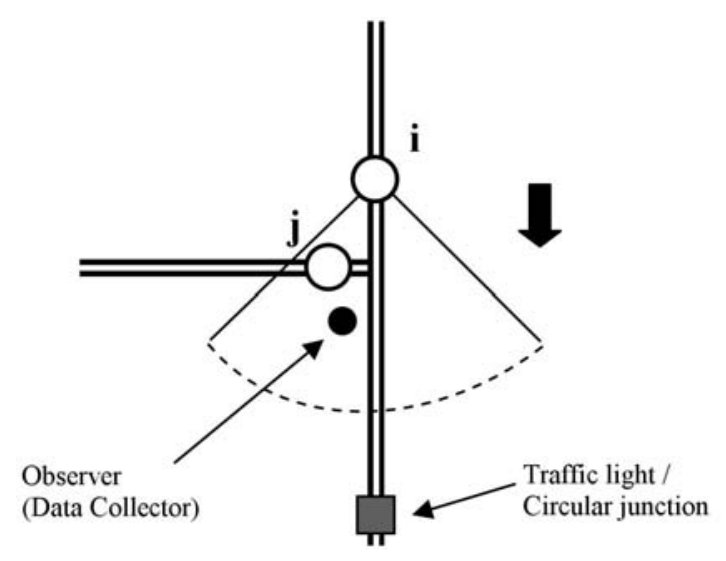

Figure 2: Observing a Social Interaction

there was no other intersection, or side road, present within commuter $i$ 's visual capacity.

When recording commuter choices, we positioned ourselves on the sidewalk (or footpath) near the waiting commuter $j$, and faced commuter $i$ as he or she approached. Such a close proximity (3 to 5 metres) enabled us to clearly observe commuter choices and attributes. To minimise monitoring effects on commuter behaviour, the observer did not wear any (familiar) uniform or distracting clothing, and tried to act in a relaxed and disinterested manner (as one would if waiting for someone).

An observation, or commuter interaction, is then recorded if commuter $i$ approaches $j$, and either stops or does not stop for $j$. If commuter $i$ does not stop and give way, commuter $j$ is then observed multiple times (as 'waiting'). That is, commuter $j$ is matched with a number of different $i$ 's, and once an $i$ stops for a $j$, we have a so-called 'match', then consequently a new $j$ arrives. It is also possible to observe the same $i$ multiple times if and only if he or she stops and gives way to more than one $j$ in succession 6

The sample consists of 959 social interactions between commuters $i$ and $j$ (Table 1 ). As we only observe 380 commuter $j$ s, this implies that on average every second or third $i$ stopped for a $j: 7$ The number of commuter $i$ s observed is 955, which is four less than the number of observed interactions. This inequality is due to $i$ stopping for exactly two $j \mathrm{~s}$ in a row on four separate occasions.

In addition to observing commuter choices, we gathered a set of estimated commuter attributes (type or class of vehicle, gender of driver, perceived age of driver, the presence of other passengers), and a set of field-specific variables (location, time of day, and weather conditions). The commuter attributes were coded by the same observer (the first author), meaning that any observer induced bias is constant across observations. Table 1 defines these variables and presents summary statistics.

\footnotetext{
${ }^{6}$ An interaction, or observation, was strictly counted only when commuters $i$ and $j$ had taken their initial positions and were judged to have observed each other. That is, in the case where $i$ stops for a $j$, and immediately continues on his or her journey without taking notice of the next waiting $j$, an interaction was not recorded between $i$ and the latter agent (the 'next $j$ ').

${ }^{7}$ The longest wait by $j$ (in terms of the number of commuter $i$ s that passed by and did not stop) was 13 , with the $14^{\text {th }} i$ stopping and giving way. In this instance, commuter $j$ was a 65 year old female driving a high status $(=3)$ four-wheel drive (jeep).
} 
Table 1: Variable Definitions and Sample Commuter Characteristics

\begin{tabular}{|c|c|c|c|}
\hline \multirow[t]{2}{*}{ Variable } & \multirow[t]{2}{*}{ "Description } & \multicolumn{2}{|c|}{ "Mean (Std. Dev.) } \\
\hline & & Commuter $i$ & Commuter $j$ \\
\hline Age & Perceived years of age & $37.61(12.55)$ & $36.47(12.80)$ \\
\hline Gender & $=1$ if male & $0.514(0.50)$ & $0.509(0.50)$ \\
\hline Vehicle type/class & $\begin{aligned}= & 0 \text { if inexpensive, old (e.g. } 1985 \text { Nissan Bluebird) } \\
& 1 \text { if lower class: average, not new (e.g. } 2000 \text { Toyota Camry) } \\
& 2 \text { if middle class: average, new (e.g. } 2010 \text { Toyota Camry) } \\
& 3 \text { if upper class: expensive, luxury (e.g. } 2008 \text { BMW E90) }\end{aligned}$ & $1.88(0.95)$ & $1.71(0.91)$ \\
\hline Vehicle size & $=1$ if large $4 \mathrm{WD}$ (e.g. Range Rover, BMW X5) & $0.26(0.44)$ & $0.18(0.38)$ \\
\hline Peers present & $=1$ if other passengers present & $0.27(0.45)$ & $0.24(0.43)$ \\
\hline No. of individuals & & 955 & 380 \\
\hline Time of day & $=1$ if morning peak-hour, $0700-0900$ AEST & \multicolumn{2}{|c|}{$0.53(0.50)$} \\
\hline Neighbourhood & $\begin{aligned}= & 1 \text { if relatively poor, Median house price }=\$ 525,000 \\
& 2 \text { if relatively rich, Median house price }=\$ 635,000 \\
& 3 \text { if rich, Median house price }=\$ 790,000\end{aligned}$ & \multicolumn{2}{|c|}{$2.03(0.82)$} \\
\hline Weather Conditions & $\begin{aligned}= & 0 \text { if rain } \\
& 1 \text { if clouds } \\
& 2 \text { if sunshine }\end{aligned}$ & \multicolumn{2}{|c|}{$1.35(0.67)$} \\
\hline No. of observations (interactions) & & \multicolumn{2}{|c|}{959} \\
\hline
\end{tabular}

Note: 'Age' is based on a subjective estimate by the observer and is coded as $18,25,35,45,55$ or 65 . 'Vehicle class' is based on the following car price estimates (in AUD): Class $0(\$ 100-\$ 5,000)$, Class $1(\$ 5,001-\$ 25,000)$, Class $2(\$ 25,001-\$ 60,000)$, and Class $3(>\$ 60,000)$. Median house prices for each 'Neighbourhood' are obtained from Realestate.com.au $\rightarrow$ Suburb Profiles (January 2011). 
Table 2: Level of Altruism by Group

\begin{tabular}{lcc}
\hline \hline & Altruism Rate & $\begin{array}{c}\text { Test of Difference } \\
\left(\widehat{p_{1}}-\widehat{p_{2}}\right)\end{array}$ \\
\hline Overall $(n=959)$ & $0.396(0.49)$ & \\
Men $(n=489)$ & $0.42(0.49)$ & 0.11 \\
Women $(n=470)$ & $0.37(0.48)$ & \\
Young $(n=585)$ & $0.35(0.48)$ & 0.00 \\
Mature $(n=374)$ & $0.48(0.50)$ & 0.04 \\
High Status $(n=187)$ & $0.38(0.49)$ & 0.00 \\
Average Status $(n=409)$ & $0.47(0.50)$ & \\
Low Status $(n=363)$ & $0.32(0.47)$ & 0.14 \\
Large size vehicle $(n=173)$ & $0.35(0.48)$ & \\
Standard size vehicle $(n=786)$ & $0.41(0.49)$ & 0.00 \\
Peers present $(n=232)$ & $0.60(0.49)$ & \\
Peers not present $(n=727)$ & $0.33(0.47)$ & \\
\hline \hline
\end{tabular}

Note: 'Altruism rate' is the proportion of commuter $i$ s that chose to stop for commuter $j$. High status if vehicle class = 3; Average status if vehicle class $=2$; Low status if vehicle class $\leq 1$. Young if age $\leq 35$; Mature if age $>35$. Standard deviations in parentheses. Test of difference between sample proportions is based on $H_{0}: p_{1}-p_{2}=0$. The resulting p-values are reported in the third column. 


\subsection{Methodology}

To provide insights into altruistic preferences, we make use of the inherent discrete choice nature of the observed social interactions. We consider a structural modelling approach, and let $U_{i}^{a}$ be the utility that commuter $i$ derives from performing the altruistic act, $a$, of stopping for $j$. Similarly, $U_{i}^{s}$ denotes the utility payoff from not stopping, i.e. being selfish, $s$. Then, commuter $i$ chooses to stop if and only if $U_{i}^{a}>U_{i}^{s}$. We assume commuter $i$ 's utility depends on observed own and commuter $j$ 's attributes, $X_{i}$ and $X_{j}$; a vector of field-specific variables, $Z_{i}$; and an idiosyncratic preference shock, $\epsilon_{i}{ }^{8}$ Specifically, we assume a random utility model of the form

$$
U_{i}^{a}-U_{i}^{s}=\alpha^{\prime} X_{i}+\beta^{\prime} X_{j}+\theta^{\prime} X_{i} X_{j}+\gamma^{\prime} Z_{i}+\epsilon_{i}
$$

where $X_{i} X_{j}$ represents interactions between the attributes of commuter $i$ and $j$. These interaction terms account for the fact that $i$ 's preferences over $j$ 's attributes may also depend on his own attributes. Of particular interest are the interactions of gender $\left(G_{i} G_{j}\right)$ and status $\left(S_{i} S_{j}\right)$. The parameter $\theta$ is then interpreted as an adjustment in tastes given the social interaction between $i$ and $j$. For example, in the case of gender, the interaction term leads to the following expression $\left(\beta+\theta^{\prime} G_{j}\right) G_{i}$, where the sum inside the parentheses represents the overall taste parameter on the gender of commuter $i$. Such a specification allows us to identify different types of social discrimination. To avoid difficulty in interpreting the interaction terms (Ai and Norton 2003), we estimate a linear probability model (rather than a logit or probit):

$$
\operatorname{Pr}\left\{\text { i stops for } \mathrm{j} \mid X_{i}, X_{j}, Z_{i}\right\}=\alpha^{\prime} X_{i}+\beta^{\prime} X_{j}+\theta^{\prime} X_{i} X_{j}+\gamma^{\prime} Z_{i}
$$

where we assume the error term to be orthogonal to all individual and field characteristics, $E\left(\epsilon_{i} \mid X_{i}, X_{j}, Z_{i}\right)=0.9$

There are two main competing interpretations for the effects of a variable in $X_{i}$ (or $X_{j}$ ) on the utility of stopping. One is that it represents the inverse of the opportunity costs (i.e. comes from $U_{i}^{s}$ ) and the other is that it represents the warm glow of stopping (i.e. comes from $U_{i}^{a}$ ). Given that we only observe the sign of $U_{i}^{a}-U_{i}^{s}$ via the observed choices, we cannot generically assign an effect to either underlying cause. However, in some cases we can make a plausibility argument for one or the other. It is for instance highly unlikely that the characteristics of the person waiting would affect the opportunity cost of stopping, and hence more likely that the effects of $X_{j}$ reflect altruism parameters. The same also holds for the effects of the interaction $X_{i} X_{j}$. On the other hand, the effects of a 'time of the day' variable (part of $Z_{i}$ ) may well reflect the opportunity cost of commuters.

\footnotetext{
${ }^{8}$ The unobserved choice attributes and tastes, $\epsilon_{i}$, include, for example, various costs of stopping or being altruistic, such as the psychological cost of having to think and care about others in society.

${ }^{9}$ Less than $2.4 \%$ of predictions fall outside of the $[0,1]$ probability range. The results on the main effects are robust to both logit and probit specificatons.
} 


\section{Results}

\subsection{Who Stops?}

Of the total choices made (by commuter $i$ ), approximately 39.6 percent correspond to acts of altruism, i.e. sacrifices made in the form of stopping for others. This overall degree of altruism is relatively high and differs across socioeconomic groups (Table 2). The observed proportion is somewhat greater, but within a similar range, as that documented by Andreoni and Miller (2002) in a two-party dictator game based on the distribution of 'tokens'. The authors find that about 30 percent of the subjects gave tokens to others in order to equalise the monetary payoffs between parties. However, admittedly the context is very different and it is difficult to compare the costs involved to the individual altruists. Similarly, if we ignore differences in methodology and context, the average commuter seems to be more generous than household members who participated in a recent charitable giving study, and made donations about 25 percent of the time (Landry et al. 2006). Our finding seems to be consistent with the slightly higher rates of giving observed in other dictator games, where close to 50 percent of subjects gave money away to others (Camerer 2003). Overall, a finding that about 40 percent of people display some degree of altruism is firmly within the range found in other contexts.

Based on the raw data, male commuters stopped at a rate of 42 percent, compared to 37 percent by females. This difference is not significant $(z=1.58)$, indicating that on average males and females are very similar. Andreoni and Vesterlund (2001) also find no gender differences in altruism based on an initial comparison of sample means in their version of the dictator game. What is perhaps of more interest is whether men are more likely to stop for women than for other men, and vice versa. We explore this type of question below.

High status individuals have a lower propensity to stop (0.38) than average status individuals (0.47), however a greater propensity than low status individuals (0.32). This inverted U-shaped relationship between altruism and status contradicts the results of Andreoni (2006) who finds a U-shaped relationship between income and charitable giving among households in the United States. The lower propensity of the high status group to behave altruistically may simply be due to the higher opportunity cost of such individuals, or could alternatively depend on the status of other commuters (that is, on interactions of status, which we also explore below). Similarly, owners of large motor vehicles (e.g. a Range Rover) have a lower degree of altruism compared to persons travelling in standard size vehicles (0.35 vs. 0.41), however the difference is not statistically significant. As mentioned earlier, this 'vehicle size' effect could also (partially) reflect the status concerns of commuters.

Observed mean rates of altruism also differ by age group: mature people, aged 45 or older, are significantly more altruistic than the young. This result supports the hypothesis that more mature people tend to be more patient commuters, and thereby have a higher propensity to stop for others. The observed age effect is consistent with existing studies that find age and social preferences to be linked (List 2004; Reece 1979; Feldstein and Taylor 1976). For example, List (2004) finds a positive relationship between age and the probability of giving in a number of different experimental field settings, including a 
sportscard show, a university fundraising event, and a television game show.

\subsection{Who Stops for Whom?}

Table 3 presents the regression results from three different model specifications, where in models 2 and 3 we include an additional variable indicating the decision to stop by the commuter in front of commuter $i . \sqrt[10]{10}$ The results in the first column of Table 3 (model 1) show the joint importance of the characteristics of both commuter $i$ and $j$, where the coefficients are directly interpretable as marginal effects. These estimates support most of the general findings from the raw data, and can be interpreted as follows:

Men are 22 percent more altruistic than women if the waiting individual (commuter $j$ ) is a woman. On the other hand, this marginal effect significantly decreases from 0.22 to 0.04 if commuter $j$ is also a male (hence, a male is 4 percent more likely to stop for another male than a female is likely to stop for a female). The obvious interpretation is that we are looking at a form of politeness of men towards women, which in itself is a social norm of altruism by men towards women (whether originally engendered by ulterior motives or not). Similarly, females are 15 percent more likely to act altruistically if the waiting commuter is a male rather than a female (thus, a female is 15 percent more likely to stop for a male than a female is likely to stop for a female). This result is consistent with previous experimental studies based on dictator games that find women to give significantly less to other women than they do to men or persons of unknown gender (see Ben-Ner et al. 2004). Based on these gender interaction effects, women seem to discriminate against the same sex more than men (that is, the estimated degree of altruism is lower when the social interaction involves two females as opposed to two males). At the same time, men discriminate in favour of the opposite sex relatively more than women (the estimated degree of altruism is higher when the social interaction involves a male $i$ and a female $j$, compared to a female $i$ and a male $j$ ). Taken as a whole, the probability of observing a kind act is greatest when a female commuter $j$ awaits a male commuter $i\left(M_{i} F_{j}\right){ }^{11}$

Higher status individuals have a 0.18 lower probability of receiving a kind treatment from others of low status, and this marginal effect improves to negative 0.13 if the decision maker (commuter $i$ ) is of similar (high) status. The finding supports the presence of envy, or jealousy, within society, as well as some degree of altruism displayed by high status individuals for others of similar status. Furthermore, individuals travelling in larger motor vehicles ('jeeps') have a 14 percent lower probability of sacrifice for others than those driving a standard size car, however this effect is cancelled when $i$ and $j$ both occupy large vehicles. The fact that low-status, high-status, and jeep-driving individuals are all relatively more likely to stop for each other (than for other types) generally supports the idea of 'like dispensing kindness on like', or the notion of assortative matching among humans (see Becker and Murphy 2000).

Mature-aged individuals are 10 percent more likely to elicit kindness than the young

\footnotetext{
${ }^{10}$ Due to experimenter induced variation in the 'neighbourhood' and 'time of day' variables, i.e. changes in field location and time breaks, and simply no presence of a commuter in front of $i$, we end up with 27 missing observations in the 'Decision of Commuter $_{i-1}$ ' variable (models 2 and 3 ).

${ }^{11}$ In Table 3, Female $_{i}{ }^{*}$ Female $_{j}\left(F_{i} F_{j}\right)$ is the reference (or base) gender interaction term. Thus, the estimated interaction effects are: $\widehat{\theta}_{F_{i} F_{j}}=0.000 ; \widehat{\theta}_{M_{i} M_{j}}=0.044 ; \widehat{\theta}_{F_{i} M_{j}}=0.150$; and $\widehat{\theta}_{M_{i} F_{j}}=0.221$.
} 
(confirming results from the raw data), with interactions of age playing no significant role in commuter behaviour. As hypothesised earlier on the basis of opportunity costs, people seem to be more selfish (by 5 percent) early on in the day which is the main time period when they drive to work, however the result is marginally insignificant at the 10 percent level.

\subsection{Peer Effects}

From the raw data in Table 2, we find the presence of peers to have a strong influence on choice behaviour as commuters show sacrifice more than 50 percent of the time when other passengers are present, and act a lot more 'selfishly' otherwise. Also, although not reported in Table 2, about 42 percent of individual decison makers 'followed the leader', in that they mimicked the altruistic act performed in front of them (by the previous or leading commuter ' $\left.i-1^{\prime}\right)$. This type of behaviour can be seen as a wider form of peer effects relating to the following of (or compliance with) a social norm (Becker 1974). That is, commuter $i-1$ 's kind act is replicated by commuter $i$ in order for the latter agent to not feel as an outcast from the rest of society ${ }^{12}$

Turning back to the estimation results from model 1, that controls for a number of other commuter characteristics, we find the presence of peers to increase the degree of altruism by a notable 25 percent. Thus, peer pressure has the greatest relative impact on the estimated individual degree of altruism, a finding that is consistent with recent studies that estimate a strong positive relationship between peer pressure and altruism (see, for example, Bandiera et al. 2005; Meer 2010). Additionally, individuals interacting in richer neighbourhoods possess a 5 percent higher propensity to stop for others relative to those interacting in poorer areas, suggesting some degree of positive sorting across neighbourhoods (see Becker and Murphy 2000; Card et al. 2008).13

From the second column of Table 3 (model 2), the decision to stop by the commuter in front of commuter $i$ (commuter ' $i-1$ ') has a small positive influence (0.024) on the likelihood that $i$ also stops, however the result is statistically insignificant. This outcome indicates a lack of aggregate peer effect from the behaviour of other commuters. Nevertheless, such a result can hide more differentiated behaviour, which is why in model 3 we include a set of interactions with the decision of commuter ' $i-1$ '. The estimated marginal effects can be interpreted as the weights attached by $i$ to the decision of the previous decision maker that are a function of the characteristics of both ' $i$ ' and ' $i-1$ '. To test whether the altruistic decisions of others are important for commuter choice behaviour, we performed an $F$-test of the joint significance of the coefficients on the 'Decision of Commuter $_{i-1}$ ' terms. The results indicate that the added terms in model 3 are jointly significant $(p$-value $=0.003)$ and thus help to explain commuter choices.

The estimates from model 3 suggest that the decision of commuter ' $i-1$ ' plays a greater role in altruistic behaviour if ' $i-1$ ' is of high status, however this effect decreases when both decision makers are of high status. Thereby, low status individuals prefer to imitate,

\footnotetext{
${ }^{12}$ The highest number of 'followers' observed in a row was 5 . On eight occasions the number of 'followers' observed in a row was $\geq 3$.

${ }^{13}$ However, such a wealth effect could be difficult to identify and interpret within our data as commuters, who reside elsewhere, could simply be passing through the observed neighbourhoods.
} 
or act like, others of higher status, but the sequence of high status decision makers reduces the rate of imitation by approximately 50 percent (from 0.11 to 0.05 ). Interestingly, 'large' commuters are more likely to follow the lead of other 'large' commuters, than are other 'smaller' commuters. More precisely, individuals driving a four-wheel drive have a 0.54 higher probability of replicating an altruistic act by others who also own a four-wheel drive, relative to commuters in standard size cars. This finding again reinforces the interpretation that 'like is kind to and mimics like', hence the idea of positive sorting among commuters.

Overall, the strong observed tastes for altruism in the presence of relevant others, as well as the high proportion of commuters replicating the kind acts by others, suggests that people respond to social pressure and norms that attach respect and honour (see Bodner and Prelec 2002; Fehr and Fischbacher 2003; Benabou and Tirole 2006).

\section{Conclusions}

This paper reports on observed acts of altruism from a unique setting involving naturally matched pairs of commuters. By observing real decisions of individual commuters on whether or not to stop (give way) for others, we derived a number of behavioural insights. Overall, we found evidence of a high degree of altruism among commuters in society, and significant group heterogeneity in choice behaviour. Older individuals were more likely to stop for others. Men seem to discriminate in favour of the opposite gender slightly more than women, while women discriminate against the same sex more than men. High status individuals were found to be less likely to receive a kind treatment unless the decision maker is also of high status. Also, the presence of passengers inside the same vehicle makes drivers behave more altruistically.

The implications for social science are to help reinforce the findings of existing research on altruism and contradict that of others. We thus find a role for peer effects on altruism in line with Bandiera et al. (2005) and Meer (2010), social sorting consistent with Becker and Murphy (2000) and Card et al. (2008), gender differences that complement those from Ben-Ner et al. (2004), and an age effect similar to List (2004). However, our results on the inverted U-shaped relation between wealth and altruism are contrary to the findings by Andreoni (2006) and Hoffman (2010).

The results on altruism have some practical significance in that both households and policy makers face the question of whom they can trust to make altruistic decisions. Governments often face this question when looking for independent regulators and judges. Households face this question when it comes to asking advice about sensitive matters such as the education of their children, whether or not they should start a business, and whether or not to migrate. The results from this paper would suggest that they should turn to 'older people of the same social status', i.e. elders from the same group. Another tentatively useful implication is the use of one's peers: when surrounding individuals by others they seem to behave in a more altruistic manner, which points to the importance of informal peer-monitoring mechanisms (see Arnott and Stiglitz 1991).

There are a number of clear limitations to a study on the commuting behaviour of close to a thousand car drivers in the city of Brisbane, Australia. One concerns the 
representativity of inner-city Brisbane for the rest of the world. Another issue is that the level of altruism involved is small-scale, i.e. in the order of sacrificing a few seconds of time at most for someone else. That is clearly not on a par with large charitable donations, raising children, sacrificing oneself for a country, or other much more substantial acts. A final limitation is that one cannot definitively say what kind of altruism is involved. The altruistic behavior may be a habit, a conscious wish to please others, or, as previously argued by Andreoni (1989, 1990), List (2007) and DellaVigna et al. (2009), because a person wants to gain personal admiration or feel better about themselves. 


\section{References}

Ai, C. and Norton, E. (2003) Interaction Terms in Logit and Probit Models, Economics Letters, 80, 123-129.

Andreoni, J. (1989) Giving with Impure Altruism: Applications to Charity and Ricardian Equivalence, Journal of Political Economy 97, 1447-58.

Andreoni, J. (1990) Impure Altruism, and Donations to Public Goods: A Theory of Warm-Glow Giving, Economic Journal, 100, 464-77.

Andreoni, J. (2006) Philanthropy, in L.A Gerard-Varet et al. (Eds.), Handbook of Giving, Reciprocity, and Altruism, Elsevier/North Holland, Amsterdam.

Andreoni, J. and Miller, J. (2002) Giving According to GARP: An Experimental Study of Rationality and Altruism, Econometrica, 70, 737-53.

Andreoni, J. and Vesterlund, L. (2001) Which is the Fair Sex? Gender Differences in Altruism, Quarterly Journal of Economics, 116, 293-312.

Arnott, R. and Stiglitz, J. (1991) Moral Hazard and Nonmarket Institutions: Dysfunctional Crowding Out or Peer Monitoring? American Economic Review, 81, 179-90.

Bandiera, O., Rasul, I., and Barankay, I. (2005) Social Preferences and the Response to Incentives: Evidence from Personnel Data, Quarterly Journal of Economics, 120, 917-62.

Becker, G. (1971) The Economics of Discrimination, 2nd ed., University of Chicago Press, Chicago.

Becker, G. (1974) A Theory of Social Interactions, Journal of Political Economy, 82, 1063-93.

Becker, G. and Murphy, K. (2000) Social Economics: Market Behavior in a Social Environment, Harvard University Press, Cambridge MA.

Becker, G., Murphy, K., and Werning, I. (2005) The Equilibrium Distribution of Income and the Market for Status, Journal of Political Economy, 113, 282-310.

Beetsma, R. and Schotman, P. (2001) Measuring Risk Attitudes in a Natural Experiment: Data from the Television Game Show Lingo, Economic Journal, 111, 821-48.

Benabou, R. and Tirole, J. (2006) Incentives and Prosocial Behavior, American Economic Review, 96, 1652-78.

Ben-Ner, A., Kong, F., and Putterman, L. (2004) Share and Share Alike? Intelligence, Socialization, Personality and Gender-Pairing as Determinants of Giving, Journal of Economic Psychology, 25, 581-89. 
Berk, J., Hughson, E., and Vandezande, K. (1996) The Price is Right, But are the Bids? An Investigation of Rational Decision Theory, American Economic Review, 86, 954-70.

Bodner, R. and Prelec, D. (2002) The Diagnostic Value of Actions in a Self-Signaling Model. In The Psychology of Economic Decisions, Vol. 1, Isabelle Brocas and Juan D. Carillo, eds: Oxford University Press, Oxford.

Camerer, C. (2003) Behavioral Game Theory: Experiments in Strategic Interaction, Princeton University Press, New York.

Card, D., Mas, A., and Rothstein, J. (2008) Tipping and the Dynamics of Segregation, Quarterly Journal of Economics, 123, 177-218.

Carpenter, J. and Myers, C. (2010) Why Volunteer? Evidence on the Role of Altruism, Image and Incentives, Journal of Public Economics, 94, 911-20.

Carpenter, J. and Seki, E. (2010) Do Social Preferences Increase Productivity? Field Experimental Evidence from Fishermen in Toyama Bay, Economic Inquiry, forthcoming.

Clark, A., Frijters, P., and Shields, M. (2008) Relative Income, Happiness and Utility: An Explanation for the Easterlin Paradox and Other Puzzles, Journal of Economic Literature, 46, 95-144.

Cooper, D. and Kagel, J. (2009) Other Regarding Preferences: A Selective Survey of Experimental Results in: J. Kagel and A. Roth, eds., The Handbook of Experimental Economics vol. 2, forthcoming.

Croson, R. and Gneezy, U. (2009) Gender Differences in Preferences, Journal of Economic Literature, 47, 448-74.

DellaVigna, S., List, J., and Malmendier, U. (2009) Testing for Altruism and Social Pressure in Charitable Giving, NBER working paper no. 15629.

Fehr, E. and Fischbacher, U. (2003) The Nature of Human Altruism, Nature, 425, 785-91.

Fehr, E. and Schmidt, K. (2006) The Economics of Fairness, Reciprocity and Altruism Experimental Evidence and New Theories. In Handbook on the Economics of Giving, Recipcrocity and Altruism, Serge-Christophe Kolm and Jean Mercier Ythier, eds: 61591, Elsevier, Amsterdam.

Feldstein, M. and Taylor, A. (1976) The Income Tax and Charitable Contributions, Econometrica, 44, 1201-22.

Fisman, R., Iyengar, S., Kamenica, E., and Simonson, I. (2006) Gender Differences in Mate Selection: Evidence From a Speed Dating Experiment, Quarterly Journal of Economics, 121, 673-97.

Fisman, R., Iyengar, S., Kamenica, E., and Simonson, I. (2008) Racial Preferences in Dating, Review of Economic Studies, 75, 117-32. 
Frank, R. (1999) Luxury Fever. Why Money Fails to Satisfy in an Era of Excess, Free Press, New York.

Hitsch, G., Hortacsu, A., and Ariely, D. (2010) Matching and Sorting in Online Dating, American Economic Review, 100, 130-63.

Hoffman, M. (2010) Does Higher Income Make You More Altruistic? Evidence from the Holocaust, Review of Economics and Statistics, forthcoming.

Johansson-Stenman, O. and Martinsson, P. (2006) Honestly, Why Are You Driving a BMW? Journal of Economic Behavior and Organization, 60, 129-46.

Karlan, D. and List, J. (2007) Does Price Matter in Charitable Giving? Evidence from a Large-Scale Natural Field Experiment, American Economic Review, 97, 1774-93.

Landry, C., and Lange, A., List, J., Price, M., and Rupp, N. (2006) Towards an Understanding of the Economics of Charity: Evidence from a Field Experiment, Quarterly Journal of Economics, 121, 747-82.

Leider, S., Mobius, M., Rosenblat, T., and Do, Q. (2009) Directed Altruism and Enforced Reciprocity in Social Networks, Quarterly Journal of Economics, 124, 1815-51.

Levitt, S. (2004) Testing Theories of Discrimination: Evidence from the Weakest Link, Journal of Law and Economics, 47, 431-52.

Levitt, S. and Dubner, S. (2009) SuperFreakonomics: Global Cooling, Patriotic Prostitutes, and Why Suicide Bombers Should Buy Life Insurance, William Morrow Publishing.

Levitt, S. and List, J. (2007) What Do Laboratory Experiments Measuring Social Preferences Reveal About the Real World?, Journal of Economic Perspectives, 21, 153-74.

List, J. (2004) Young, Selfish and Male: Field Evidence of Social Preferences, Economic Journal, 114, 121-49.

List, J. (2006a) The Behavioralist Meets the Market: Measuring Social Preferences and Reputation Effects in Actual Transactions, Journal of Political Economy, 114, 1-37.

List, J. (2006b) Friend Or Foe? A Natural Experiment of the Prisoner's Dilemma, Review of Economics and Statistics, 88, 463-71.

List, J. (2007) On the Interpretation of Giving in Dictator Games, Journal of Political Economy, 115, 482-93.

Luttmer, E. (2005) Neighbors as Negatives: Relative Earnings and Well-Being, Quarterly Journal of Economics, 120, 963-1002.

Meer, J. (2010) Brother, Can You Spare a Dime? Peer Pressure in Charitable Solicitation, Journal of Public Economics, forthcoming. 
Reece, W. S. (1979) Charitable Contributions: New Evidence on Household Behavior, American Economic Review, 69, 142-51.

Shang, J. and Croson, R. (2009) A Field Experiment in Charitable Contribution: The Impact of Social Information on the Voluntary Provision of Public Goods, Economic Journal, 119, 1422-39.

Veblen, T. (1899) The Theory of the Leisure Class, [Originally published by Macmillan New York], George Allen and Unwin, London. 
Table 3: Who Stops for Whom?

Linear Probability Model Estimation Results

\begin{tabular}{|c|c|c|c|c|c|c|}
\hline & \multicolumn{2}{|c|}{ Model 1} & \multicolumn{2}{|c|}{ Model 2} & \multicolumn{2}{|c|}{ Model 3} \\
\hline & m.e. & s.e. & m.e. & s.e. & m.e. & s.e. \\
\hline Mature $_{i}$ & $0.103^{* * *}$ & $(0.036)$ & $0.099^{* * *}$ & $(0.036)$ & $0.127^{* * *}$ & $(0.039)$ \\
\hline Mature $_{i} \times$ Mature $_{j}$ & 0.029 & $(0.046)$ & 0.034 & $(0.047)$ & 0.040 & $(0.046)$ \\
\hline Male $_{i}$ & $0.221^{* * *}$ & $(0.041)$ & $0.232^{* * *}$ & $(0.041)$ & $0.240^{* * *}$ & $(0.042)$ \\
\hline Male $_{i} \times$ Male $_{j}$ & $-0.177^{* * *}$ & $(0.041)$ & $-0.179^{* * *}$ & $(0.042)$ & $-0.178^{* * *}$ & $(0.042)$ \\
\hline Female $_{i} \times$ Male $_{j}$ & $0.150^{* * *}$ & $(0.042)$ & $0.159^{* * *}$ & $(0.042)$ & $0.168^{* * *}$ & $(0.041)$ \\
\hline Status $_{j}$ & $-0.183^{* * *}$ & $(0.018)$ & $-0.185^{* * *}$ & $(0.019)$ & $-0.210^{* * *}$ & $(0.019)$ \\
\hline Status $_{i} \times$ Status $_{j}$ & $0.052^{* * *}$ & $(0.007)$ & $0.053^{* * *}$ & $(0.007)$ & $0.067^{* * *}$ & $(0.008)$ \\
\hline$J_{e e p_{i}}$ & $-0.144^{* * *}$ & $(0.047)$ & $-0.156^{* * *}$ & $(0.047)$ & $-0.167^{* * *}$ & $(0.046)$ \\
\hline $\mathrm{Jeep}_{i} \times \mathrm{Jeep}_{j}$ & $0.124^{*}$ & $(0.074)$ & $0.133^{*}$ & $(0.074)$ & $0.142^{*}$ & $(0.074)$ \\
\hline Peers Present $_{i}$ & $0.246^{* * *}$ & $(0.034)$ & $0.244^{* * *}$ & $(0.034)$ & $0.237^{* * *}$ & $(0.033)$ \\
\hline Neighbourhood & $0.046^{* *}$ & $(0.018)$ & $0.050^{* * *}$ & $(0.019)$ & $0.049^{* * *}$ & $(0.019)$ \\
\hline Time of day & -0.047 & $(0.030)$ & -0.041 & $(0.030)$ & -0.039 & $(0.030)$ \\
\hline Weather Conditions & -0.003 & $(0.021)$ & -0.005 & $(0.021)$ & -0.011 & $(0.021)$ \\
\hline Decision $_{i-1}$ & & & 0.024 & $(0.031)$ & -0.051 & $(0.072)$ \\
\hline Decision $_{i-1} \times$ Mature $_{i-1}$ & & & & & 0.031 & $(0.058)$ \\
\hline Decision $_{i-1} \times$ Mature $_{i-1} \times$ Mature $_{i}$ & & & & & $-0.149^{*}$ & $(0.079)$ \\
\hline Decision $_{i-1} \times$ Male $_{i-1}$ & & & & & 0.049 & $(0.059)$ \\
\hline Decision $_{i-1} \times$ Male $_{i-1} \times$ Male $_{i}$ & & & & & 0.000 & $(0.072)$ \\
\hline Decision $_{i-1} \times$ Status $_{i-1}$ & & & & & $0.112^{* * *}$ & $(0.038)$ \\
\hline Decision $_{i-1} \times$ Status $_{i-1} \times$ Status $_{i}$ & & & & & $-0.049^{* * *}$ & $(0.015)$ \\
\hline Decision $_{i-1} \times$ Jeep $_{i-1}$ & & & & & 0.008 & $(0.067)$ \\
\hline Decision $_{i-1} \times J_{\text {Jeep }}{ }_{i-1} \times J_{e e p_{i}}$ & & & & & $0.536^{* *}$ & $(0.223)$ \\
\hline Number of observations: & 959 & & 932 & & 93 & \\
\hline
\end{tabular}

Note: Outcome variable $y_{i}=1$ if individual $i$ stops for $j$, and 0 otherwise. 'Decision of Commuter Con $^{\prime}$ ' equals 1 if the commuter in front of commuter $i$ (i.e. commuter ' $i-1^{\prime}$ ) stopped for a $j$, and 0 otherwise. Constant terms included in models. Robust standard errors in parentheses. ${ }^{*} p<0.10,{ }^{* *} p<0.05,{ }^{* * *} p<0.01$. 